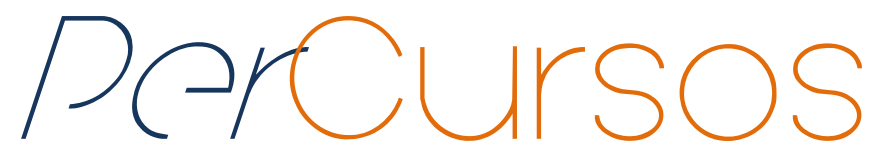

\title{
Legislação ambiental e urbanística no Brasil: o Caso Costão do Santinho Resort em Florianópolis/SC ${ }^{1}$
}

\section{Resumo}

Este trabalho analisa o desenvolvimento dos grandes empreendimentos turísticos em Florianópolis, utilizando o caso Costão do Santinho Resort como objeto de estudo. O estudo aqui proposto requer um referencial teórico e um método que possibilite a compreensão das relações sociais, econômicas e ambientais, responsáveis pelas políticas públicas, que vão determinar, na prática, a garantia ou não da preservação e distribuição equitativa dos recursos naturais para as próximas gerações. A hipótese é que existe uma tendência à efetivação dos interesses dos grandes empreendimentos turísticos em Florianópolis, como é o caso Costão do Santinho Resort, afrontando as legislações ambiental e urbanística, impactando de forma irreversível o meio ambiente, descaracterizando as comunidades tradicionais e acentuando a segregação socioespacial com a legitimação do Poder Público. Logo, é preciso equilibrar preservação ambiental e desenvolvimento econômico.

Palavras-chave: Política nacional do meio ambiente; Lei da ação civil pública; Estatuto da cidade; Impactos socioambientais.

\section{Gabriel Bertimes Di Bernardi Lopes}

Doutor em Geografia pela Universidade Federal de Santa

Catarina - UFSC. Professor da Universidade do Estado de Santa Catarina - UDESC. Brasil

gabrieldibernardi@hotmail.com

\section{Para citar este artigo:}

LOPES, Gabriel Bertimes Di Bernardi. Legislação ambiental e urbanística no Brasil: o caso Costão do Santinho Resort em Florianópolis/SC. Revista PerCursos. Florianópolis, v. 16, n.32, p. 121 - 142, set./dez. 2015.

DOI: 10.5965/1984724616322015121

http://dx.doi.org/10.5965/1984724616322015121

\footnotetext{
${ }^{1}$ Esta pesquisa é parte da tese "Origem, desenvolvimento e impactos dos grandes empreendimentos turísticos em Florianópolis”, que teve apoio da CAPES.
} 


\title{
Environmental and urban law in Brazil: the case Costão do Santinho Resort in Florianópolis/SC
}

\begin{abstract}
This paper analyzes the social and environmental dynamics established in the development of large tourist developments in Florianopolis, using the case Costão do Santinho Resort as object of study. The principles of environmental and urban law with emphasis on the National Environmental Policy are identified, the Law of Public Civil Action and the City Statute, beyond the phases of urbanization and the emergence of large tourist complexes in the capital of Santa Catarina. Finally, we analyze the social and environmental relations of the enterprise screen with the government, with social movements and local communities. Therefore, the study proposed here requires a theoretical and methodological framework that allows the understanding of the social, environmental and economic, policy makers, which will determine, in practice, the guarantee or not the preservation and fair distribution of natural resources for future generations. The hypothesis is that there is a tendency to effect the interests of large tourist developments in Florianopolis, such as the case Costão do Santinho Resort, defying principles of environmental law, environmental and town planning laws, irreversibly impacting the environment, mischaracterizing traditional communities and emphasizing the sociospatial segregation with the legitimacy of the government. So we need to balance the relationship between the use of natural resources and economic developmen.
\end{abstract}

Keywords: National environmental policy; Law on public civil action; Statute of the city; Social and environmental impacts. 


\section{Introdução}

Esta pesquisa analisa a dinâmica socioambiental instaurada no desenvolvimento dos grandes empreendimentos turísticos em Florianópolis, utilizando o caso Costão do Santinho Resort como objeto de estudo. O caso estudado traz uma série de conflitos ligados à construção deste empreendimento turístico de grande porte, associado a outros empreendimentos como a Marina do Costão e o Condomínio Residencial Costão Golf, pertencentes aos Grupos Costão do Santinho Empreendimentos Turísticos e CostãoVille Empreendimentos. Pesquisa esta baseada em análise de campo, nos pareceres do Estudo de Impacto Ambiental (EIA) e do Relatório de Impacto ao Meio Ambiente (RIMA), bem como na Ação Civil Pública (ACP) impetrada pelo Ministério Público Federal (MPF) contra o Costão do Santinho Empreendimentos Turísticos.

A hipótese é que existe uma tendência à efetivação dos interesses dos grandes empreendimentos turísticos em Florianópolis, como é o caso Costão do Santinho Resort, afrontando as legislações ambiental e urbanística, impactando de forma irreversível o meio ambiente, descaracterizando as comunidades tradicionais e acentuando a segregação socioespacial com a legitimação do Poder Público.

O presente artigo identifica na primeira seção a legislação ambiental e urbanística vigente no Brasil com destaque para a Política Nacional do Meio Ambiente e o Estatuto da Cidade. Na segunda seção, são identificadas fases do processo de urbanização de Florianópolis, relacionando o surgimento dos grandes empreendimentos turísticos na capital catarinense. E, por fim, na terceira seção, há um estudo sucinto sobre o caso Costão do Santinho Resort. Atualmente, grandes empresas ditam a organização do mercado hoteleiro em Florianópolis, em consonância com a busca da elevação dos lucros, mas em detrimento da qualidade de vida do cidadão florianopolitano.

O estudo aqui proposto apoia-se em um referencial teórico e em um método, que possibilita a compreensão das múltiplas determinações políticas, econômicas, culturais e naturais, responsáveis pela urbanização e evolução da legislação urbanística na capital catarinense. Dessa forma, utilizar-se-á como instrumento de análise a categoria axial ao marxismo desenvolvida por Milton Santos, denominada formação socioespacial. Santos 
(1977) salienta que a história não se escreve fora do espaço, da mesma maneira que não há sociedade fora espaço. O espaço é social.

Logo, demonstra a impossibilidade de dissociar a dimensão espacial dessa categoria, configurando-se em perspectiva teórica essencial nos estudos geográficos. Essa categoria envolve as noções de desenvolvimento desigual e da sobrevivência de estruturas capitalistas das formações anteriores.

Em mesma linha de pensamento, pode-se dizer que o estudo da lei não é dissociado das condições concretas ou do contexto do qual ela emana; visto que, do contrário, cair-se-ia na metafísica da lei ou no enfoque supra-histórico do direito, já bastante superado nas últimas décadas.

\section{Legislação ambiental e urbanística no Brasil}

Destaca-se a importância dos princípios do direito ambiental como orientadores da legislação ambiental e urbanística. No caso estudado são discutidos os princípios do desenvolvimento sustentável e da participação.

Machado (2006) salienta que o princípio do desenvolvimento sustentável decorrente, sobretudo, dos debates da Conferência Mundial do Meio Ambiente realizada no ano de 1972, em Estocolmo, foi utilizado pela primeira vez em 1987, no Relatório Brundtland. Considera basicamente que os recursos ambientais não são inesgotáveis, formando um contexto de que não devem ser utilizados sem considerar esse fato. A relação entre economia e meio ambiente deve existir, não sem conflitos, ainda que nos marcos de uma economia capitalista, em que o capital e seu modo de acumulação em si são consumidores de recursos e transformadores da natureza, quase sem limites, esta relação seja instável. Nessa linha, busca-se o desenvolvimento, mas de forma sustentável projetada, para que os recursos existentes de hoje não se esgotem.

Outro princípio fundamental do direito ambiental é o princípio da participação, que visa à conscientização e ao controle social sobre o manejo do ambiente. A comunidade tem o direito de participar das assembleias comunitárias e audiências públicas sobre meio ambiente, com o objetivo de garantir um ambiente ecologicamente equilibrado para as presentes e as futuras gerações. Diante dos interesses difusos e 
coletivos da sociedade, a participação visa à conservação do meio ambiente, tendência essa que teve início na segunda metade do século XX, conforme destaca Machado (2006).

Verifica-se a relevância que os princípios ambientais possuem no atual sistema jurídico brasileiro, podendo ser aplicados nas diferentes áreas do ordenamento espacial. Auxiliam o legislador nas elaborações das normas, nas interpretações das mesmas e também em sua aplicação nas diferentes esferas jurídicas, orientando leis como a Lei da Política Nacional do Meio Ambiente, a Lei da Ação Civil Pública e o Estatuto da Cidade.

A Lei da Política Nacional do Meio Ambiente, entre muitas finalidades, trouxe para o mundo do Direito o conceito de meio ambiente como objeto específico de proteção em seus diversos aspectos. Instituiu o Sistema Nacional de Meio Ambiente (SISNAMA), que oferece o planejamento de atividades integradas de múltiplos órgãos governamentais através de uma política nacional para o setor. Estabelece a obrigação de o poluidor reparar os danos causados, baseado no princípio da responsabilidade objetiva (ou sem culpa) em ação movida pelo Ministério Público.

Os instrumentos são meios, medidas e procedimentos pelos quais o Poder Público executa a política ambiental que deve focar-se sempre na preservação, melhoria e recuperação do meio ambiente e no equilíbrio ecológico, salienta Séguin (2000).

Conforme Machado (2006), as expressões Estudo de Impacto Ambiental (EIA) e Relatório de Impacto Ambiental (RIMA) representam documentos distintos. O EIA tem maior abrangência e engloba o RIMA, abrange o levantamento da literatura científica e legal pertinente, trabalhos de campo, análises de relatório e a própria redação do relatório. O EIA é um dos instrumentos da Política Nacional do Meio Ambiente, encontrado no artigo $9^{\circ}$, III, da Lei 9.638/81. As noções de estudo e avaliação se completam através do preceito constitucional e dos preceitos de legislação ordinária na Lei $6.803 / 80$. As verificações e análises do ElA terminam por um juízo de valor, ou seja, avaliação favorável ou não ao projeto. Não se admite um EIA que se abstenha de emitir a avaliação do projeto.

A obrigatoriedade do prévio EIA para a construção de projetos potencial ou efetivamente poluidores é uma delegação constitucional. No entanto, demonstra-se que 
a norma constitucional traz muitas dúvidas e divergências, no que se refere à sua adequada compreensão, de acordo com Antunes (2006).

O Relatório de Impacto Ambiental (RIMA) deve então expressar todas as conclusões do Estudo de Impacto Ambiental. O conteúdo do EIA e do RIMA vinculam, entretanto, o órgão público ambiental com a equipe multidisciplinar responsável. Quando o órgão público já possui informações que devam fazer parte do EIA e do RIMA, deve passar tais informações para a equipe multidisciplinar, que deverá confrontar e integrar as informações recebidas com as que ela levantar. Do contrário, fragmentar-se-ia o EIA e o RIMA, o que viciaria todo o procedimento. Para Machado (2006), o órgão público não poderá dispensar qualquer dos elementos de conteúdo do EIA e do RIMA.

Outra lei ambiental importante, assim como a Lei da Política Nacional do meio Ambiente, é a Lei 7.347, de 24.07.1985, que normatizou a Ação Civil Pública como instrumento processual específico para a defesa do meio ambiente e de outros interesses difusos e coletivos. Como destaca Milaré (2004), esta lei fez com que a agressão ambiental finalmente se tornasse um caso de justiça. Através dessa lei, associações civis ganharam força para agir em juízo e, juntamente com o Ministério Público (MP), puderam, em parte, frear as inconsequentes agressões ao meio ambiente.

Cumpre observar que o Meio Ambiente ganha muito em ter o Ministério Público (MP) como um dos atores da Ação Civil Pública, munido de poderes para uma atuação eficiente e independente. O inquérito civil, atribuição constitucional do Ministério Público, servirá para uma eficiente colheita de provas para embasar a ação judicial. Destaca-se que essa Instituição vem propondo uma elevada quantidade de ações civis públicas ambientais, em que no polo passivo estão os Governos Federal ou Estadual, além de empresas públicas ou privadas, salienta Machado (2006).

O Estatuto da Cidade, Lei n. 10.257 de 10 de julho de 2001, é outra lei imprescindível para a obtenção do desenvolvimento urbano sustentável. Seu objetivo é garantir à população o uso da propriedade urbana em prol do bem coletivo, utilizando uma série de instrumentos no controle dos impactos urbanos.

São instrumentos utilizados para o fim desta lei: planos nacionais, regionais e estaduais de ordenamento do território e de desenvolvimento econômico e social; 
planejamento das regiões metropolitanas, aglomerações urbanas e microrregiões; planejamento municipal, incluindo elaboração de plano diretor, parcelamento e uso do solo, zoneamento ambiental, plano plurianual, diretrizes orçamentárias e gestão orçamentária participativa, além dos planos setoriais; imposto sobre a propriedade predial e territorial urbana (IPTU); desapropriações, tombamento de imóveis ou mobiliários urbanos, instituição de unidades de conservação e zonas especiais de interesse social, usucapião especial do imóvel urbano, outorga onerosa do direito de construir e de alteração de uso, operações urbanas consorciadas, regularização fundiária, assistência técnica e jurídica para as comunidades menos favorecidas, além da realização de referendos populares e plebiscitos; estudo prévio de impacto ambiental (EIA) e estudo prévio de impacto de vizinhança (EIV).

Para Rolnik (1988), o Estatuto da Cidade é uma legislação pioneira de regulação no âmbito federal para as políticas urbanas sem a ficção tecnocrática dos velhos planos diretores, que prometiam tudo, mas que não possuíam instrumentos para realizar o que propunham. Ele apresenta três características principais que o tornam inovador. Novos instrumentos urbanísticos voltados a induzir mais do que normatizar as formas de uso e ocupação do solo, novas estratégias de gestão que incorporam a ideia de participação direta dos cidadãos em processos decisórios sobre o destino da cidade e ampliação das possibilidades de regularização das posses urbanas.

Todo esse conjunto de normas e leis configura o contexto jurídico que envolve a dinâmica socioambiental instaurada no processo de implantação dos grandes empreendimentos turísticos em Florianópolis, inclusive no caso do Costão do Santinho Resort.

\section{A urbanização e o surgimento dos grandes empreendimentos turísticos em Florianópolis}

É de suma importância destacar as três fases do processo de urbanização de Florianópolis, divididas por Bastos (2000). Salienta o autor que o processo de urbanização da capital catarinense é vinculado ao processo de ascensão e decadência da pequena produção mercantil açoriana e à divisão territorial e social do trabalho, impulsionada pelo desenvolvimento industrial no Brasil. As fases de urbanização, segundo esse autor, são as 
seguintes: $1^{\mathrm{a}}$ fase - vinculada à condição de praça exportadora (século XVIII até 1875$) ; 2^{\mathrm{a}}$ fase — vinculada à condição de praça importadora (1875 até 1960); $3^{\mathrm{a}}$ fase — vinculada à inserção no contexto capitalista industrial brasileiro (1960 aos dias atuais), no caso da capital, referente à expansão do aparelho de Estado e comércio. Ainda nessa fase, ocorre a expansão do turismo, em particular, como nova forma de acumulação e de circulação do capital, com o surgimento de grandes empreendimentos de alto impacto ambiental, com investimento privado nacional e internacional.

A inserção da capital catarinense no contexto capitalista industrial brasileiro $\left(3^{\mathrm{a}}\right.$ fase de urbanização de Florianópolis) resultou em forte resistência por parte dos capitais comerciais locais, principais beneficiados nas fases precedentes e que, porém, foram substituídos por capitais comerciais nacionais, a exemplo das grandes redes de lojas de departamentos como Colombo, Arapuã e Ponto Frio, além da rede de supermercados Pão de Açucar, bem como por capitais regionais, a exemplo das redes de lojas de materiais de construção Cassol e Casas da Água, e a rede de supermercados Imperatriz.

Os desdobramentos desta fase fazem-se sentir em: atividade pesqueira (incentivos à pesca industrial via Sudepe); processo de balnearização de Florianópolis; modernização das instituições públicas por meio da instalação das universidades públicas, a exemplo da Universidade Federal de Santa Catarina (UFSC) e da Universidade para o Desenvolvimento de Santa Catarina (UDESC), além de outras estatais como Centrais Elétricas de Santa Catarina (CELESC), Banco do Estado de Santa Catarina (BESC), Telecomunicações de Santa Catarina (Telesc), Departamento Nacional de Obras de Saneamento (DNOS), Departamento Nacional de Estradas de Rodagem (DNER), etc.; bem como obras de infraestrutura, a exemplo da construção da BR 101, dos aterros da Baía Sul e do Saco dos Limões, das pontes Colombo Sales e Pedro Ivo Campos e de diversas outras obras, cujo montante de investimentos públicos per capita foi um dos mais elevados do país no período militar. Foi na terceira fase de urbanização que se iniciou a expansão imobiliária e seu consequente processo especulativo, sobretudo voltado ao turismo em Florianópolis. Isso se dá a partir da década de 1970 e se intensifica na década de 1990.

Conforme salienta Peres (2008), a partir dos anos 80 os preços dos terrenos próximos à orla duplicam em média com relação aos mais distantes, indicando uma 
acelerada tendência de valorização crescente das bordas de água ou orla de Santinho, cujo processo de ocupação se agrava no verão. Este modelo de concentração na orla, há décadas se reproduz tanto na parte insular como continental da microrregião de Florianópolis.

A crescente destruição dos ecossistemas na orla principalmente a partir da década de 80 é resultado de um modelo de ocupação que privilegia a orla como objeto de valorização fundiária e imobiliária. A partir de 1985 se intensifica a especulação imobiliária nesses locais e nos balneários de Florianópolis com os grandes empreendimentos que promovem severos impactos socioambientais.

Sobre as principais causas que poderiam ser enumeradas para explicar o vertiginoso crescimento urbano dos municípios da orla atlântica catarinense, Bastos (2000) destaca: 1) dinamismo econômico brasileiro e catarinense; 2) expansão do mercado ligado ao turismo; 3) a reserva de valor na aquisição de imóveis em áreas desvalorizadas, mas com potencial turístico; 4) a melhoria das infraestruturas urbana e rodoviária como força atrativa de investidores, mão de obra, novos moradores e turistas.

O vertiginoso crescimento da população brasileira e notadamente da orla marítima entre 1970 e 2000 denuncia o avanço do crescimento urbano; enquanto a população urbana no Brasil multiplicou-se por 2,64 vezes, a população urbana de Santa Catarina e dos municípios do litoral catarinense multiplicou-se por, respectivamente, 3,7 e 4,6 vezes. Eis a representação do "fenômeno da litoralização", na verdade, presente desde sempre no Brasil, de acordo com a análise de Pereira (2007).

Logo, trata-se de área que historicamente sofre demasiada pressão exercida pela ação antrópica, a exemplo de Florianópolis, em que a transição do rural para o urbano significou danos severos ambientais e sociais. Veado (1998) salienta que a principal atividade da Ilha de Santa Catarina resume-se tradicionalmente no setor terciário, porque Florianópolis canaliza para si a prestação de serviços, educação, comércio, profissões liberais e administração pública. Nas últimas décadas, o turismo vem surgindo como o principal meio de vida de um sem número de pessoas e instituições. A abertura de vias de comunicação quase sempre mal planejadas, que, cedo, acabam criando outros problemas, como inexistência de rede de águas pluviais, impermeabilização das pistas de 
rolamento com escoamento superficial dificultado pelo relevo plano, deficiência na distribuição de água e energia elétrica, deficiência na pavimentação, dentre outros.

A expansão urbana sem planejamento efetivo leva à ocupação irregular das encostas, planícies de inundação, dos manguezais, das restingas e não tem merecido atenção das autoridades, ou, quando muito, apenas parcial. Acrescentem-se o lançamento diretamente no mar de esgotos domésticos e de restaurantes e de hotéis, fossas sépticas mal dimensionadas e mal construídas, que deterioram o lençol aquífero, o lixo nas praias, a falta de infraestrutura hoteleira e o número incipiente de restaurantes e bares para a quantidade de turistas.

Atualmente, grandes empresas ditam a organização do mercado imobiliário em Florianópolis, em consonância com a busca da elevação dos lucros em detrimento da qualidade de vida do cidadão florianopolitano. O empreendimento denominado Costão do Santinho Resort, propriedade do Costão do Santinho Empreendimentos Turísticos, enquadra-se como representação dessa realidade, além de outros empreendimentos, como o caso do Il Campanário Villaggio, do grupo financeiro Habitasul, localizado em Jurerê Internacional, também no Norte da Ilha de Santa Catarina. 


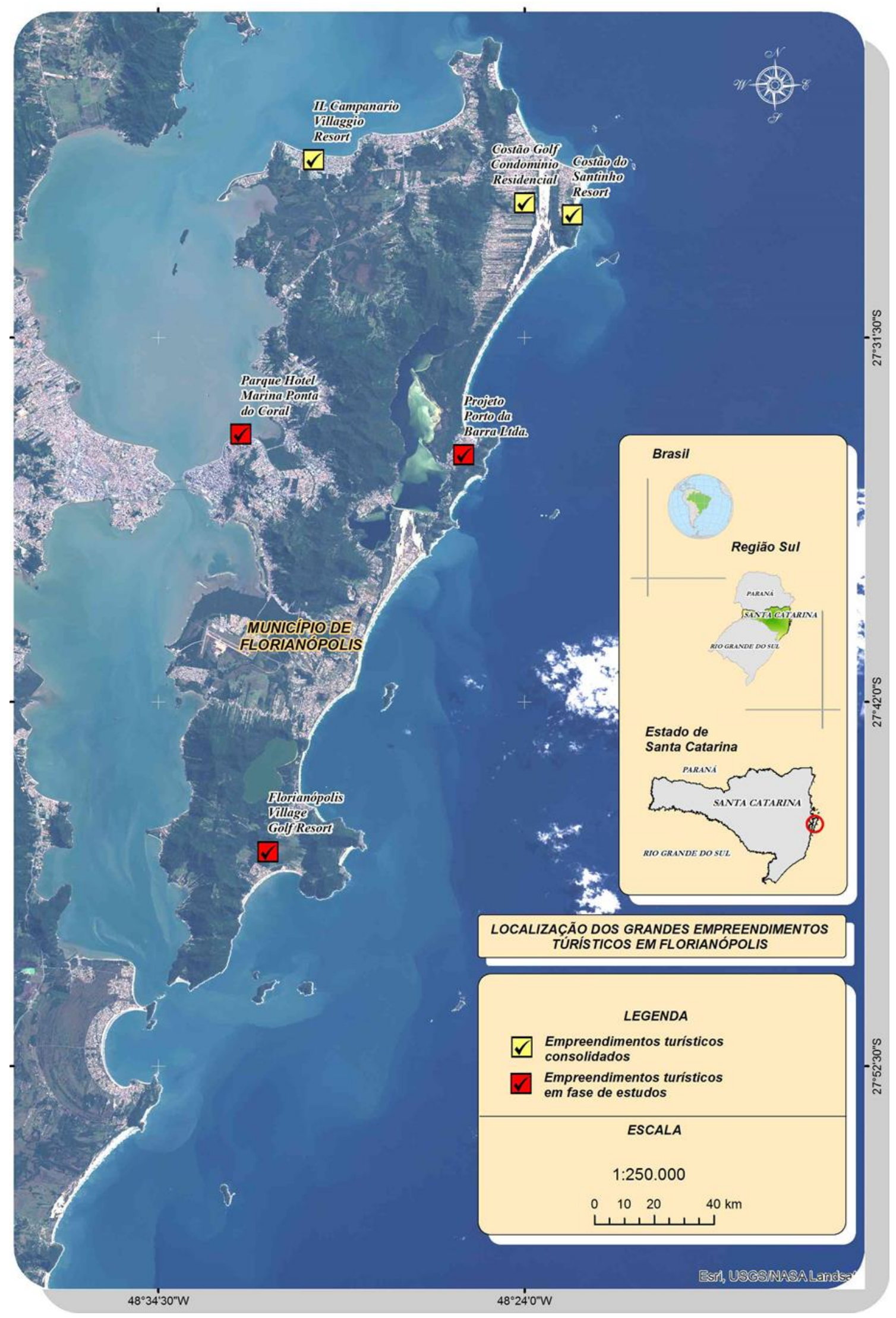

Figura 1 - Localização dos grandes empreendimentos turísticos em Florianópolis Fonte: Gabriel Bertimes Di Bernardi Lopes/2015. 


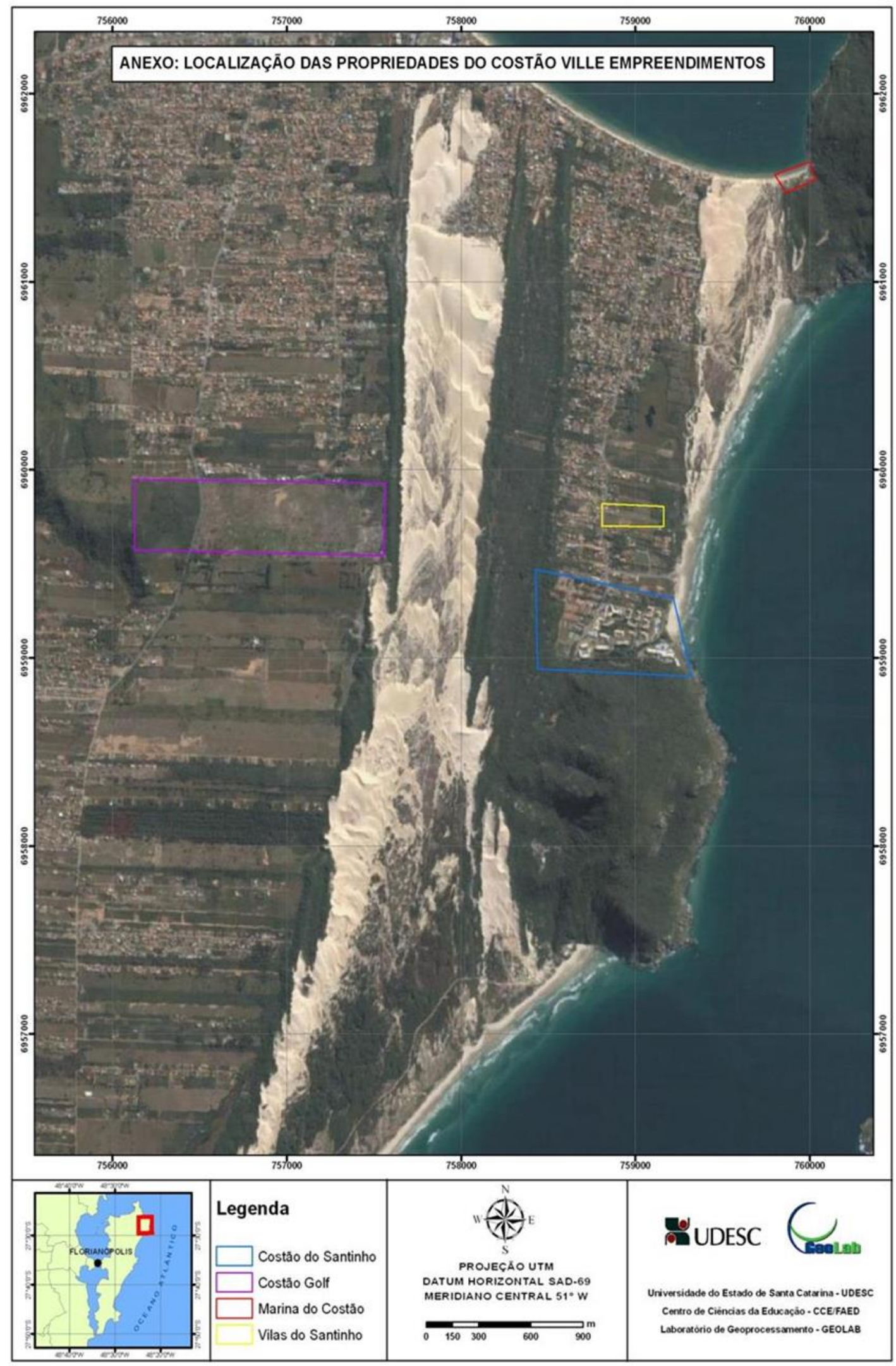

Figura 2 - Localização das propriedades do grupo CostãoVille Empreendimentos Fonte: Gabriel Bertimes Di Bernardi Lopes/2007. 


\section{O caso Costão do Santinho Resort}

De acordo com o EIA (1995), o Costão do Santinho Resort está localizado no extremo nordeste da Ilha de Santa Catarina, Distrito de Ingleses do Rio Vermelho, na Praia do Santinho. O empreendimento está situado no Morro das Aranhas, em uma parte relativamente plana do promontório. A área é separada do empreendimento por um canal natural, com vales pronunciados e vegetação arbórea. A drenagem segue em curso paralelo ao canal, situando-se em cotas mais elevadas, com vales pouco diferenciados e com vegetação predominantemente arbustiva e próxima ao oceano.

Segundo ACP nº 96.0007478-o (1995), o Ministério Público Federal, através de seus agentes, no uso de suas atribuições, com base nos dispositivos da Lei 7347/85, impetrou em dezembro de 1996 uma Ação Cautelar Preparatória da Ação Civil Pública. O processo $\mathrm{n}^{\circ}$ 96.0007478-0 apresentou pedido de liminar contra Santinho Empreendimentos Turísticos. Também foi processado o IBAMA, Instituto Brasileiro do Meio Ambiente e dos Recursos Naturais Renováveis, além da FATMA, Fundação de Amparo ao Meio Ambiente.

Os réus foram citados por uma série de ilegalidades. Pode-se destacar o fato de o complexo turístico do Costão do Santinho, ocupar uma enorme área na região norte da Ilha de Santa Catarina, incluindo inúmeros terrenos de marinha. A empresa, através dos anos, foi reunindo posses e propriedades na região, projetando um empreendimento que contempla hotelaria, vilas residenciais e outros equipamentos.

As obras da empresa ré, como se observa do documento de autuação da FATMA, de 1988, iniciaram sem qualquer pedido de licenciamento ambiental. Advertido, o empreendedor obteve da FATMA, órgão licenciador estadual, em 1989, a Licença Ambiental Prévia, sem exigência de estudo de impacto ambiental. Agindo o órgão em desrespeito à lei e com completa irresponsabilidade, frente a esta área, com ocorrência de ecossistema bastante frágil, rico em biodiversidade (dunas, restinga, mata atlântica e promontório). Note-se nos documentos da FATMA, o reconhecimento da fragilidade do ecossistema.

Continuando em seu desapego às normas pelas quais deveria zelar, determinou o órgão, por sua Diretoria à época, a análise de cada uma das etapas do empreendimento como obra autônoma, sem considerações maiores pelo impacto total. Assim, desde 1989, 
várias foram as Licenças Ambientais de Instalação deferidas, omitindo-se o órgão acerca da perda da validade da LAP original, e da ausência de EIA/RIMA.

Agraciado com tais equívocos, pôde o empreendedor continuar edificando sem o cumprimento das exigências legais, constatando-se não só a ocupação dos terrenos alodiais, mas também da área de marinha (União Federal), considerada pela própria municipalidade como Área Verde de Lazer, onde só são permitidos equipamentos de uso público (advertência que consta também do documento da FATMA).

Para dar início às obras do Hotel, que não possui Licença Ambienta Prévia, foi tentada terraplanagem e erguida pequena edificação, com supressão de vegetação de preservação permanente, o que foi suficiente para alarmar a população local e os turistas, que realizaram abaixo-assinado contra a execução do projeto.

Em janeiro de 1989 chegou ao conhecimento da Procuradoria o início efetivo da ocupação inadequada e ilegal. Foram determinadas vistorias pela FATMA, IBAMA e Polícia de Proteção Ambiental, o que resultou em embargo administrativo dos órgãos estadual e federal, impedindo temporariamente os avanços da ré.

Quanto ao destacamento militar de proteção ambiental, teve a ousadia o representante da empresa no local, de apresentar ao policial uma cópia de licença ambiental de uma das Vilas Residenciais em construção fora da área do promontório, como se a mesma fosse a do hotel.

As vistorias geraram auto de infração do IBAMA, encaminhado ao Ministério Público Estadual, versando sobre supressão de mata ciliar e de mata atlântica.

Do laudo do IBAMA assinado por um engenheiro agrônomo e um biólogo, destaca-se que, em vistoria realizada em 03 de janeiro de 1996, uma equipe técnica constatou o corte de vegetação nativa em parte do terreno onde agora está construído o mirante. O que motivou a notificação $\mathrm{n}^{\circ}$ 051258-B solicitando a apresentação dos documentos do licenciamento ambiental pertinentes.

Apresentados esses documentos, constata-se que não havia a necessária autorização de desmatamento para a construção do mirante, ficando comprovado, portanto, que os empreendedores descumpriram a legislação em vigor. 
Ao efetuar vistoria em 25 de março de 1996 para a elaboração de laudo técnico, constatou-se a construção do mencionado mirante e a ocorrência do fato apontado pela vistoria anterior. Entretanto, verificou-se que parte do terreno foi demarcada para o início da obra, o que resultou na supressão de uma faixa de 70m por 1,5m de vegetação, atingindo a área de preservação permanente. Obviamente, não houve, e nem poderia haver autorização para tal corte de vegetação. De acordo com a demarcação feita, ficou evidente que a construção do empreendimento naquele terreno implicaria na destruição da vegetação de preservação permanente, o que legalmente não poderia ser feito.

No tocante ao licenciamento ambiental do empreendimento, foi anexada a cópia da autuação efetuada pela FATMA, em 28 de janeiro de 1996, cuja infração é descrita como uma construção em área de preservação permanente sem prévia autorização. Ou seja, não há licenciamento ambiental com validade que permita a implantação do empreendimento, e nem poderá haver, posto que a construção do mesmo signifique a destruição de considerável parcela de área de preservação permanente.

Considerando os resultados da vistoria, concluiu-se que o empreendimento em tela não reuniria condições legais para prosperar. Foi constatado pelos órgãos ambientais que a empresa construíra um mirante ou local de visitação para clientes, localizado na parte alta do terreno.

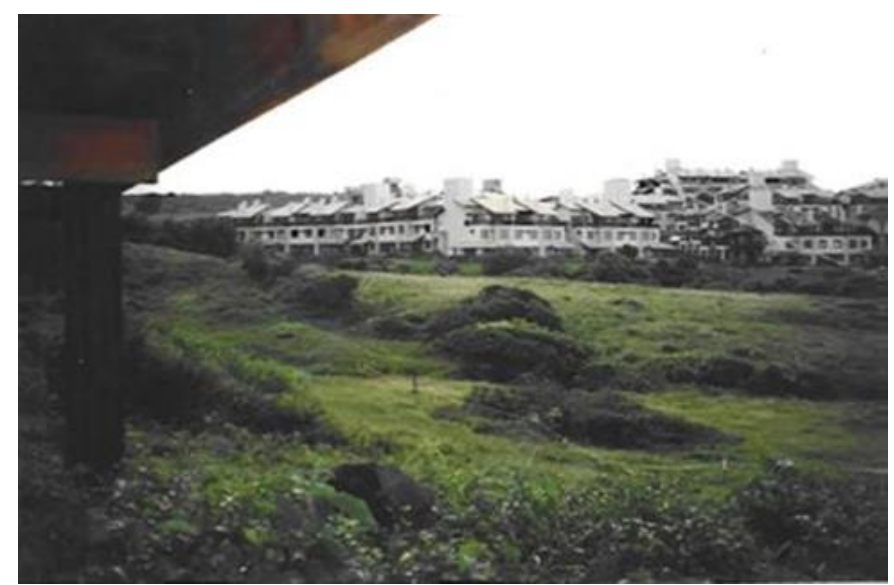

Figura 3 - Mirante com o empreendimento ao fundo Fonte: ACP n 96.0007478-0/1996.

Para tanto, além da alteração do local pela construção, foi queimada e cortada parte da vegetação do entorno. Inclusive do curso d'água. Existe, ainda, cercamento de 
parte do acesso ao promontório e ao sítio arqueológico do Costão do Santinho. O obstáculo supracitado já era objeto de notificação da autoridade municipal, como se comprova documentalmente.

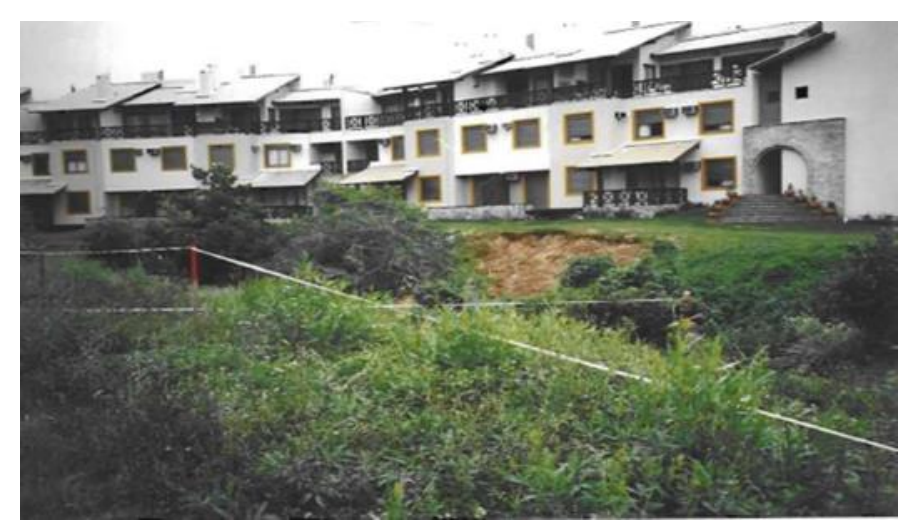

Figura 4 - Marcação do IBAMA da vegetação em APP na margem do curso d'água no empreendimento Fonte: ACP n 96.0007478-0/1996.

Aparentemente, a empresa ré tem por hábito iniciar suas obras e só depois procurar as autorizações da administração, quando o faz. Infelizmente, mais uma vez a atuação dos órgãos ambientais não é suficiente para afastar o risco para o patrimônio natural e turístico da Ilha de Santa Catarina.

Em 04 de dezembro de 1996, diversos telefonemas foram recebidos na Procuradoria e no Comando de Polícia Ambiental, denunciando o recomeço de atividades no local, mais precisamente com a presença de máquinas pesadas e alterações no promontório. Foram abertas valas em frente à área projetada para o Hotel, aproximadamente há 15 metros das pedras que contornam aquele acidente geográfico.

Em relação ao promontório, à vegetação ainda existente ou em estágio de regeneração, às consequências para todo o ecossistema e o procedimento de licenciamento irregular, preferiu o IBAMA (órgão central/coordenador do SISNAMA, conforme Lei 6938/81) "lavar as mãos", omitindo-se e pedindo a atuação da FATMA.

Quanto à FATMA, também foi descoberto pelo MPF que fora expedida Licença Ambiental Prévia (LAP) para o Hotel, já em setembro de 1996. Ou seja, uma nova LAP foi expedida apenas para o hotel, em manobra evidente para evitar a discussão da nulidade da LAP anterior, do licenciamento sem EIA/RIMA e o prejuízo de áreas de preservação permanente. 
Em 27 de novembro de 1996, dois meses após a assinatura da LAP referida, o Diretor-Geral substituto da FATMA garantiu ao MPF que, nenhuma nova licença ambiental foi expedida, e que o embargo anterior estava no CONSEMA (Conselho Estadual do Meio Ambiente), para apreciação de recurso administrativo. Respondendo aos ofícios da Procuradoria de forma a ocultar a verdade, já que a nova LAP tinha sido deferida, sem dúvida cometeu o funcionário público ato irregular, cuja investigação foi objeto de encaminhamento à Unidade Criminal do MPF.

O Diretor-Geral da FATMA salientou que é inverídico que o empreendimento tenha iniciado suas obras, pois não possuía LAI (em 1988 também iniciou sem qualquer licença), e que a resposta anterior dizia respeito a outras etapas do complexo (previstas para área de dunas interiores afastadas do promontório), as quais igualmente estavam embargadas.

Muitas são, portanto, as irregularidades relacionadas ao famoso empreendimento turístico, fazendo-se necessária a atuação ministerial no sentido de enquadrá-lo na legislação de regência, objetivando a defesa do patrimônio natural de toda a sociedade, o respeito às leis e a penalização de seus infratores.

Quando do início das obras no Santinho, já havia sido promulgada a Carta Constitucional de 1988, a qual consagrou a exigência do estudo de impacto como dever do Poder Público (art. 225, $\S 1^{\circ}$, IV). Tal preceito, como todos os demais em matéria ambiental, insere-se no objetivo maior do ramo jurídico, qual seja a proteção do meio ambiente, finalidade que determina a validade das normas legais respectivas e a regularidade da atuação da Administração, em seus diversos níveis.

Quanto à legislação estadual, além dos regramentos da Constituição de Santa Catarina/89, especialmente o Capítulo VI- Do Meio ambiente, há que citar o Decreto 14.250/81, que regulamentou os dispositivos da Lei Estadual 5.793/81. Este decreto considera áreas de proteção especial os promontórios, as ilhas fluviais, as ilhas costeiras e oceânicas, estas quando cedidas pelo Governo Federal, as áreas de formações vegetais defensivas à erosão de encostas e de ambientes de grande circulação biológica, especialmente os mangues, os sítios de interesse recreativo, cultural e científico. 
Considera-se promontório a elevação costeira florestada ou não que compõe a paisagem litorânea do continente ou de ilhas, e área de formação defensiva à erosão de encostas e de ambientes de grande circulação biológica à região sensível ao desgaste natural onde a cobertura vegetal preserva permanentemente o solo.

Nos promontórios, numa faixa de até $\mathbf{2 . 0 0 0 ~ m e t r o s ~ d e ~ e x t e n s a ̃ o , ~ a ~ p a r t i r ~ d a ~ p o n t a ~}$ mais avançada, é proibido o corte raso da vegetação nativa, a exploração de pedreiras e outras atividades que degradem os recursos naturais e a paisagem, a edificação de prédios ou construção de qualquer natureza.

$\mathrm{Na}$ área do empreendimento existe ainda, sítio arqueológico não totalmente delimitado, sendo certo que a escavação do terreno, sem uma análise anterior por parte do Instituto do Patrimônio Histórico e Artístico Nacional (IPHAN) poderá impactar de forma irreversível patrimônio cultural porventura existente.

Pelo exposto, exigia o MPF a decisão judicial para imediata paralisação do procedimento de licenciamento irregular em tramitação na FATMA. Além de continuar suspenso o cancelamento do embargo do IBAMA, abster-se a empresa ré de efetuar qualquer alteração no promontório das Aranhas, salvo o que se faça necessário no decorrer do processo para proteção do ecossistema e do patrimônio cultural lá existente, especialmente no que diz respeito à supressão de vegetação, alteração de cursos d'água e colocação de obstáculos físicos ao acesso da população ao promontório, retirar a empresa ré os mourões de cerca existentes no local, e abster-se a empresa ré ou seus representantes da publicidade em tomo do lançamento do Hotel, haja vista a possibilidade de tal fato criar prejuízos para terceiros, conforme o direito do consumidor.

Os Procuradores da República Analúcia Hartmann, Maria Soares Cordioli, Maurício Gotardo Gerum e Roberto Luís Oppermann Thomé deram ao feito cautelar o valor de um milhão de reais.

O restaurante e o centro de eventos construídos sobre o promontório não obedeceram ao termo de ajustamento de conduta proposto pelo Ministério Público Federal (MPF). Atualmente, o empreendimento opera de forma irregular, enquanto o processo tramita na Justiça Federal. 


\section{Considerações finais}

Historicamente os recursos naturais estiveram ligados ao desenvolvimento econômico global, servindo de combustível para sustentar esse crescimento. É preciso equilibrar a relação entre a utilização dos recursos naturais e o desenvolvimento econômico, para que as próximas gerações não paguem, até mesmo com a vida, pelos erros decorrentes do mau uso de tais recursos.

É nítida a falta de fiscalização do Plano Diretor Municipal, adequando-se aos interesses do empreendimento e alterando o zoneamento em detrimento do capital privado. Os Planos Diretores acabam, muitas vezes, não garantindo a preservação dos recursos naturais.

Além da falha de fiscalização, algumas leis são pouco eficazes, como a Lei de Crimes Ambientais, que obriga a reparação dos danos ambientais cometidos e estabelece punições para os degradadores. Os danos ambientais irreversíveis e as punições previstas são multas que representam um percentual irrisório frente ao capital do empreendedor, além de penas leves que dificilmente se concretizam.

Verifica-se que muitas alterações efetuadas no Plano Diretor de Florianópolis beneficiaram diretamente grandes empreendimentos turísticos como o Costão do Santinho Resort e o Condomínio Residencial Costão Golf do Grupo CostãoVille, e o II Campanário Villaggio Resort do grupo Habitasul.

O Costão do Santinho Resort, o Condomínio Residencial Costão Golf e o II Campanário Villaggio Resort mesmo sendo objeto de ações civis públicas, e tendo sido embargados pela Justiça Federal por algum tempo, acabaram tendo as licenças ambientais concedidas e operam normalmente, sem restrições, enquanto as ações tramitam no judiciário.

Fica evidenciada uma contradição entre a apropriação do capital e o domínio do espaço, em relação à preservação do meio ambiente e o desenvolvimento socioeconômico das populações locais, que correm o risco também de serem exploradas ainda como mão de obra barata. Tal contradição leva a temáticas mais gerais, como a relacionada à questão da impossibilidade de conciliar-se o desenvolvimento sustentável, 
que é um princípio do direito ambiental, com o desenvolvimento econômico orientado por fundamentos liberais e capitalistas.

Assim pode-se concluir que: 1) a legislação ambiental e a urbanística no Brasil encontram-se historicamente na vanguarda jurídica mundial com a inserção de princípios do direito ambiental e urbanístico em suas normas antes mesmo de eles se popularizarem no debate internacional, porém muitas vezes esbarram em interesses políticos e econômicos minimizando a sua efetividade; 2) importantes instrumentos como o licenciamento ambiental e o EIA/RIMA, objetivando garantir a preservação ambiental e cultural, estão consagrados na Política Nacional do Meio Ambiente; 3) o MPF, com o advento da Lei da Ação Civil Pública, apresenta-se como um importante ator social na fiscalização e preservação dos recursos patrimoniais ambientais e culturais; 4) a partir do ano 2000 ocorre na Região Metropolitana uma explosão imobiliária, que tem como característica fundamental a participação de construtoras de outros estados, assim os padrões de concorrência e competitividade elevam-se, forçando inovações tecnológicas e estratégias empresariais mais refinadas; 5) existe uma tendência à efetivação dos interesses dos grandes empreendimentos turísticos na capital catarinense, como são os casos do Costão do Santinho Resort, do Condomínio Residencial Costão Golf e do II Campanário Villaggio Resort, afrontando princípios do direito ambiental, as legislações ambiental e urbanística, impactando de forma irreversível o meio ambiente; 6) nem sempre os interesses dos grandes empreendimentos turísticos são efetivados, por conta de forte atuação dos movimentos ambientalistas e do Ministério Público Federal na Ilha de Santa Catarina; 7) os grandes empreendimentos turísticos ocupam áreas protegidas com a legitimação do Poder Público; 8) com a cidade almejada por parte dos empresários da construção civil e do Poder Público, a Ilha de Santa Catarina segue em seu acelerado processo de degradação ambiental, descaracterização dos modos de vida tradicionais e segregação socioespacial.

Contudo, realça-se que desvendar as ações danosas ao meio ambiente, provocadas por parte dos grandes empreendimentos turísticos e do poder público, não é suficiente. Principalmente se esses dados não forem divulgados e discutidos amplamente junto a todas as comunidades envolvidas. Isso, para que, pela participação e pelo controle 
efetivo exercido pelas comunidades, seja possível aglutinarem-se forças suficientes para exigir responsabilidade do poder público na criação e no cumprimento das leis que têm por objetivo garantir a qualidade de vida da população.

Pretende-se, com o esta pesquisa, contribuir com os debates sobre os rumos socioambientais da ocupação territorial de uma cidade como Florianópolis, em uma ilha como a de Santa Catarina, exemplo típico do atual modo de urbanização do litoral brasileiro.

\section{Referências}

ANTUNES, Paulo de Bessa. Direito Ambiental. $11^{\text {a }}$ ed. Rio de Janeiro: Lúmen Júris, 2006.

BASTOS, José Messias. Urbanização, comércio e pequena produção mercantil pesqueira na ilha de santa catarina. In: SANTOS, Maurício Aurélio dos (org.). Ensaios sobre Santa Catarina. Florianópolis: Letras Contemporâneas, 2000.

BRASIL. Ministério Público Federal. Ação Civil Pública nº 96.0007478-o/SC. Brasília: Justiça Federal, 1996.

Estudo de impacto ambiental para implantação do Costão do Santinho Resort. Praia do Santinho - Distrito de Ingleses do Rio Vermelho. Florianópolis, 1995.

MACHADO, Paulo Affonso Leme. Direito ambiental brasileiro. $14^{\mathrm{a}}$ ed. São Paulo: Malheiros Editores, 2006.

MILARÉ, Édis. Direito do ambiente. $3^{\text {a }}$ ed. São Paulo: Revista dos Tribunais, 2004.

PEREIRA, Raquel Maria Fontes do Amaral. A particularidade do quadro urbano do litoral catarinense no processo de urbanização do sul do brasil. In: Anais do X Simpósio Nacional de Geografia Urbana, Universidade Federal de Santa Catarina, de 29 de outubro a 02 de novembro de 2007. Florianópolis: UFSC, 2007.

PERES, Lino Fernando Bragança. Oficinas comunitárias de planejamento urbano: uma alternativa ao Plano Diretor - Estudo de caso: Ingleses-Sul, Florianópolis. In: PEREIRA, Elson Manoel (org.). Planejamento urbano no Brasil: Conceitos, Diálogos e Práticas. $1^{\mathrm{a}}$ ed. Chapecó: Argos, 2008.

ROLNIK, Raquel. O que é cidade. São Paulo: Brasiliense, 1988.

SANTOS, Milton. Sociedade e espaço: a formação social como categoria e como método. São Paulo: Boletim Paulista de Geografia, 1977. 
SÉGUIN, Elida. O Direito ambiental: nossa casa planetária. $1^{\mathrm{a}}$ ed. Rio de Janeiro: Forense, 2000.

VEADO, Ricardo Wagner ad-Vincula. Geossistemas de Santa Catarina. Rio Claro: UNESP, 1998. 